Hedging Pressure and Futures Price Movements in a General Equilibrium Model Author(s): David Hirshleifer

Source: Econometrica, Vol. 58, No. 2 (Mar., 1990), pp. 411-428

Published by: The Econometric Society

Stable URL: http://www.jstor.org/stable/2938209

Accessed: 18/02/2011 17:37

Your use of the JSTOR archive indicates your acceptance of JSTOR's Terms and Conditions of Use, available at http://www.jstor.org/page/info/about/policies/terms.jsp. JSTOR's Terms and Conditions of Use provides, in part, that unless you have obtained prior permission, you may not download an entire issue of a journal or multiple copies of articles, and you may use content in the JSTOR archive only for your personal, non-commercial use.

Please contact the publisher regarding any further use of this work. Publisher contact information may be obtained at http://www.jstor.org/action/showPublisher?publisherCode=econosoc.

Each copy of any part of a JSTOR transmission must contain the same copyright notice that appears on the screen or printed page of such transmission.

JSTOR is a not-for-profit service that helps scholars, researchers, and students discover, use, and build upon a wide range of content in a trusted digital archive. We use information technology and tools to increase productivity and facilitate new forms of scholarship. For more information about JSTOR, please contact support@jstor.org. 


\title{
HEDGING PRESSURE AND FUTURES PRICE MOVEMENTS IN A GENERAL EQUILIBRIUM MODEL ${ }^{1}$
}

\author{
By DAVID HiRSHLEIFER
}

\begin{abstract}
Optimal futures hedging and equilibrium futures price bias are examined in a model characterized by two consumption goods, one of which has stochastically varying output, and where information arrives sequentially. Positive (negative) complementarity in consumer preferences promotes downward (upward) bias in the futures price viewed as a predictor of the later spot price.

I demonstrate that the conclusion derived from partial equilibrium analysis - that when speculators are risk averse, risk premia are a function of hedging pressure-fails in the general equilibrium analysis, so long as there are no transaction costs. A counterexample is analyzed in which, as consumers' additive logarithmic preferences are varied, producers' hedging positions change from long to short, while the futures risk premium remains unchanged. However, hedging pressure is reinstated as a force influencing risk premia in the sense that the futures price is downward biased when hedgers take short positions and is upward biased when hedgers take long positions, provided it can be assumed (as is usually valid) that fixed setup costs of trading deter consumers more than producers from participating in the futures market.
\end{abstract}

KeYWORDS: Dynamic hedging, commodity futures price bias, transaction costs, risk premia.

Two ISSUES CENTRAL to the analysis of futures markets are the determination of optimal hedging/speculative positions for the various classes of traders (e.g., producers and outsiders) and the existence of price bias, that is, deviations of the futures price from the expected value of the later spot price. A major branch of the futures pricing literature attributes bias to hedging pressure by producers. ${ }^{2}$

In the original normal backwardation theory of Keynes and Hicks, producers take short positions in the futures market to hedge their initial long positions in the commodity. Their supply of futures contracts, or hedging pressure, tends to drive down the futures price relative to the expected value of the later spot price, to generate a downward bias (normal backwardation) in the futures price. Speculators who enter on the long side of futures contracts bear a risk, and being risk-averse are therefore compensated by a positive expected profit on their positions. More recent work $^{3}$ in which producers face quantity risk as well as price risk has shown that they might take long instead of short futures positions -in which case their hedging pressure would instead promote an upward price bias ("contango"). Specifically, producers will want to hedge their overall income risk by going long if quantity is relatively variable compared to price (elastic demand) and going short in the opposite case. So upward or downward bias in

\footnotetext{
${ }^{1}$ This paper is adapted from a chapter of my dissertation at the University of Chicago. I thank my dissertation committee: D. Carlton, G. Becker, D. Diamond, C. Kahn, and L. Telser. Especially helpful comments were provided by M. Brennan, B. Trueman, and two anonymous referees of this journal. I also thank G. Constantinides, E. Fama, V. France, M. Grinblatt, S. Grossman, D. Lucas, A. Subrahmanyam, S. Titman, and S. Yeh. I am happy to acknowledge financial support from the Earhart Foundation and the Center for the Research of Security Prices at the University of Chicago.

${ }^{2}$ Some traditional sources include Keynes (1923), Hicks (1939), Stein (1961), Stoll (1979).

${ }^{3}$ Rolfo (1980), Newbery and Stiglitz (1981), Newbery (1983), Anderson and Danthine (1983), D. Hirshleifer (1988a, b).
} 
the futures price depends on whether the aggregate hedging position by producers is long or short. ${ }^{4}$

The hedging pressure literature usually assumes, first, that only a single risky security is traded, and second, that the only sources of risk in the economy are random supply/demand shocks for the futures-traded commodity. In contrast, the branch of the futures literature based on the Capital Asset Pricing Model (CAPM) allows for many risky tradable endowments. However, by assuming that equity claims to producers' future revenues are tradable, ${ }^{5}$ the traditional CAPM rules out the incentive for producers to hedge using futures; they instead trade to well-diversified portfolios along the efficient frontier. ${ }^{6}$

Both the hedging pressure and traditional CAPM models are "partial equilibrium," in the sense that they do not model the consumption choice between the futures-traded and other commodities. Instead, decisionmakers maximize expected utility derived from generalized wealth, which is equivalent to assuming only a single consumption good. The primary purpose of the current paper is to reexamine the effect of hedging on the futures risk premium within a general equilibrium (multi-good) setting. ${ }^{7}$ The paper differs from the standard hedging pressure and CAPM literatures in that (i) demand for the futures-traded commodity is determined as an optimizing consumption choice among different goods, and (ii) in selecting futures positions, individuals take into account that the relative prices of the goods they consume are changing. Allowing for more than a single consumption good makes it possible to examine how the consumption preferences such as complementarity affect equilibrium risk premia.

To investigate how hedging by producers influences risk premia, the case of zero complementarity (additive separability) is examined with both costless and costly futures trading. When trading is costless, the main pricing prediction of the hedging pressure theory is refuted. As consumer preferences vary, the spot market demand elasticity changes, causing aggregate hedging to change from short to long. Nevertheless, the futures price remains unbiased, ${ }^{8}$ so hedgers are

\footnotetext{
${ }^{4}$ A recent study by Chang (1985) lends support to this thesis, in that futures prices for grains on average rise when hedgers are short, and fall when hedgers are long.

${ }^{5}$ That is, the CAPM in effect assumes that all producers costlessly issue equity shares in their businesses.

${ }^{6}$ The models of Stoll (1979) and D. Hirshleifer (1988a) combined producer hedging with a stock market. In such a setting, the futures price bias has additive components, the first due to the futures contract's "beta" (covariance of its return with the return on the stock market portfolio of all tradable endowments), and a second due to hedging by producer's of their revenue risks from sales of the commodity. Breeden's $(1980,1984)$ general equilibrium consumption-based CAPM also allows for nontraded endowments, and therefore implicitly for producer hedging.

7 A general equilibrium literature has examined a different set of issues. J. Hirshleifer (1977), Grauer and Litzenberger (1979), Richard and Sundaresan (1981), and Breeden (1980, 1984) examine futures pricing in multi-good settings, but not the role of producer hedging in futures pricing. Stiglitz (1983) and Britto (1985) provide a number of useful results concerning hedging by producers; the current paper differs from these in that all rather than a subset of traders are concerned with two consumption goods, and in its focus on nontrading by some investors.

${ }^{8}$ The conditions discussed below leading to unbiased futures pricing are not new. However, it does not seem to have been recognized that this general equilibrium prediction conflicts with the hedging pressure prediction of recent partial-equilibrium models with risk-averse speculators.
} 
able to reduce their risk without paying a premium to speculators. Furthermore, under more general preferences there is still no presumption that producer hedging will promote futures price bias.

The source of the disagreement between the different classes of models is a neglected element in the partial-equilibrium account, the risks borne by consumers of the commodity. Here, since consumers' risks prove to be inverse to those of producers, the hedging pressures of the two groups are in opposite directions. Therefore, the two groups reduce their own type of risk by mutually hedging on the futures market, with neither receiving a premium from the other.

However, the partial-equilibrium models are certainly realistic in limiting the participation of consumers in the futures market. Owing to fixed setup costs (such as finding a broker or learning about the market), few commodity consumers trade futures ${ }^{9}$ to hedge relative price changes, despite the consumptionhedging incentives described by Breeden (1984). Randomness in the price of a single commodity such as corn is relatively inconsequential to a consumer of many commodities, but imposes a substantial risk on a specialized producer. Setup costs will therefore differentially tend to deter small consumers rather than producers of the commodity from participating in the futures market.

I show here that nonparticipation by consumers restores the effect of hedging pressure on price bias. Consider the "traditional" case in which producers hedge short (price risk outweighs quantity risk). Since the consumers who remove themselves from the futures market would have hedged long, nonparticipation creates an imbalance between the hedging pressure of producers and of the remaining consumers. Balance is restored by a downward price bias, which discourages short hedging while encouraging the remaining consumers to enlarge their long positions. The analysis therefore shows that hedging-induced futures price bias derives fundamentally from barriers to futures trading that impact differently upon consumers rather than producers. ${ }^{10}$

The paper is structured as follows. The economic setting is described in Section 1. Section 2 analyzes futures price bias and dynamic hedging strategies in markets without transaction costs. Section 3 shows how fixed setup costs of trading in the futures market affect the price bias. Section 4 concludes the paper.

\section{THE ECONOMIC SETTING}

Each individual is endowed with a stochastically variable quantity of a risky commodity $Z$ and a known quantity of the numeraire commodity $N$ ("all other

\footnotetext{
${ }^{9}$ Stock mutual funds do not trade in commodity futures, so investors who wish to include commodities in their portfolios must resort to specialized futures funds. Pension funds face regulatory constraints on trading commodity futures. Alternatively, shifting risk from growers to consumers by off-exchange forward contracting would clearly be very costly, if it operates through the intermediation of millers, bakers, and retailers at different stages in the production process.

${ }^{10}$ This explains Gray's (1960) finding that bias tends to be more pronounced in thin (low participation) futures markets.
} 
goods"). ${ }^{11}$ In the assumed regime of futures markets $(F M)$, traders can exchange only riskless claims to $Z$ and $N$. Thus, the purchase of a unit of $Z$ entitles the buyer to receive that unit in each and every state of the world. The model is therefore in real rather than nominal terms (see Grauer and Litzenberger (1979)). The market regime excludes the possibility of trading claims that are state-contingent, e.g., insurance contracts or equity shares. Spot and futures markets are assumed to be competitive, and individuals are assumed to have homogeneous beliefs.

Traders maximize expected utility by choosing consumption levels of goods $N$ (the numeraire) and $Z$ (the risky good). All individuals have identical preferences over the two goods summarized by the utility function $U(n, z)$. All consumption takes place at date $1 .^{12} \mathrm{We}$ assume that there are $S$ possible states of the world at date 1 . Information is publically revealed through a sequence of $m$ information events with binary outcomes, which are jointly conclusive. ${ }^{13}$ (I.e., together they determine the state of the world, so that $S=2^{m}$.)

The information event $j$ is a random variable $\theta^{j}$ whose possible outcomes are denoted $a^{j}$ and $b^{j}$. The history of information events through $j$ is $\left(\theta^{1}, \theta^{2}, \ldots, \theta^{j}\right)$ and will be denoted by $s^{j}$. The entire ordered sequence of information events 1 through $m$, starting at date 0 and ending at consumption date 1 , determines the final state $s^{m}$ (or more briefly, $s$ ). The initial probabilities are $\pi_{s}^{0}$ for the different states, and after later events $\theta^{1}, \ldots, \theta^{j}$, the probability of state $s$ conditional on history $s^{j}$ is denoted $\pi_{s}^{j}$.

The sequence of market trading is as follows. Each participant begins with an endowment gamble $E=\left(\bar{n} ; \bar{z}_{1}, \ldots, \bar{z}_{S}\right)$, where $\bar{n}$ is his initial (nonrandom) endowment of $N$ available for consumption at date 1 , and $\bar{z}_{s}, s=1, \ldots, S$ is his state-conditional endowed quantity of $Z$. A grower typically would be endowed with some state-distributed pattern of $Z$ (his prospective output of corn, say), while a consumer would be endowed only with $N\left(\bar{z}_{s} \equiv 0\right)$. Before the first information event, each individual trades on the futures market to a speculative gamble $T^{0}=\left(n^{0} ; z_{1}^{0}, \ldots, z_{S}^{0}\right)$. The futures transaction involves a purchases of $\xi^{0}$ units of corn at price $P^{0}$ (in units of $N$ ). (Thus, for a buyer, $z_{s}^{0}$ exceeds $\bar{z}_{s}$ by $\xi^{0}$ for each and every $s$.) After the first information event $\theta^{1}$, an individual revises his beliefs to $\pi_{s}^{1}$ and retrades (by buying or selling $\xi^{1}$ contracts at price $P^{1}$ ) to a new trading position $T^{1}$. This process of information arrival and retrading continues until $\theta^{m}$ arrives and resolves the final state of the world. Individuals

${ }^{11}$ We may interpret $Z$ as corn, say, and $N$ as noncorn consumption. The purpose of assuming a fixed endowment of $N$ is to focus on hedging pressure. The Mayers (1972) CAPM with nonmarketable assets showed that a security's risk premium is influenced not only by its covariation with nonmarketable endowments (reflecting hedging incentives), but also by covariation with marketable assets ("beta"). Stock market risk would enter the current model, if in addition to the imperfectly marketable risky endowment of $Z$, equity shares were traded on stochastic endowments of $N$.

${ }^{12}$ Introducing consumption at date 0 would not substantively alter any of the results provided here. On the other hand, multi-date consumption and resettlement would introduce considerations not addressed here.

${ }^{13}$ The binomial information process is used for tractability, as discussed further below. Cox, Ross, and Rubinstein (1979) used a binomial state process to provide insight about hedging behavior in options. Unlike their model, this paper does not assume an exogenous process for prices. 
then trade at the ultimate (spot) price $P^{m}$ to their final consumption positions $\left(n^{m} ; z_{s}^{m}\right)$. (We have listed only $z_{s}^{m}$ after the semicolon, the quantity of $Z$ in the single state actually realized.)

The individual's trading problem may then be written as

$$
\begin{aligned}
& \max _{\left\{\xi^{k}\left(s^{k}\right)\right\}} E\left[U\left(\tilde{n}^{m}, \tilde{z}^{m}\right)\right] \quad \text { subject to } \\
& n^{0}=\bar{n}-P^{0} \xi^{0}, \quad n^{k}=n^{k-1}-P^{k} \xi^{k}, \\
& z_{s}^{0}=\bar{z}_{s}+\xi^{0}, \quad z_{s}^{k}=z_{s}^{k-1}+\xi^{k} \quad(k=1, \ldots, m ; s=1, \ldots, S) .
\end{aligned}
$$

The trading strategies $\xi^{k}$ are functions of $s^{k}$, the history through $k$. The selection of the $\xi^{k}$ 's, by the trading constraints, pins down $z_{s}^{k}$ and $n^{k}$ as functions of $s^{k}$ also, a dependence which is left implicit. Prices $P^{k}$ are also functions of history. $\tilde{z}^{m}$ is a random variable that takes on value $z_{s}^{m}$ in state $s . \tilde{n}^{m}$ is also in general random, since it arises from a trading strategy which depends on stochastic information arrivals.

\section{Effective Completeness of the Futures Markets Regime}

Throughout the paper, we will make the mild assumption that the arrival of different information events leads to different prices (otherwise, perturb the endowments to shift prices slightly). This implies the following lemma (all proofs are in the Appendices).

\section{LEMMA 1: The regime of futures markets is effectively complete.}

To see why, let us define wealth contingent on state $s, W_{s}^{m}$ for an agent after all information has been revealed (when $\theta_{m}$ arrives) but prior to the final round of trading. Let contingent wealth be the value of his total holdings $n^{m-1}$ and $z_{s}^{m-1}$ of $N$ and $Z$ in state $s$, denominated in units of $N$,

$$
W_{s}^{m} \equiv n^{m-1}+P^{m} z_{s}^{m-1} .
$$

The meaning of a shift in a trader's "wealth" occurring at rounds prior to $m$ is developed formally in Appendix 1. In general, if there are enough securities to adjust the level of "wealth" achieved due to different outcomes at each information event, then the market is effectively complete. The futures contract suffices here because of the binomial information structure. ${ }^{14}$ At each event a futures position shifts wealth across outcomes, so ex ante we can calculate effective prices for transferring wealth from one final state to another. The information structure therefore allows us to exploit the tractable properties of complete markets

\footnotetext{
${ }^{14}$ It is well known that multiple trading rounds can reduce the number of long-lived securities needed to effectively complete a market. See, e.g., Kreps (1982); see Duffie and Huang (1985) for a continuous time analysis. Here, absent transaction costs, an efficient allocation is achieved using only the futures contract for the exchange of $N$ for $Z$.
} 
allocations, without eliminating the need for traders to use futures contracts. ${ }^{15}$ The binary information structure is the discrete time analog to a diffusion framework with a single state variable, in which two securities complete the market.

\section{HEDGING AND BIAS WITH ZERO TRANSACTION COSTS}

We will first examine the pricing of futures contracts in Section 2.1, and then in Section 2.2 derive conclusions about optimal hedging and its relationship to pricing.

\subsection{Futures Price Bias}

In a futures market regime with zero transaction costs, preference complementarity is an important determinant of the direction of futures price bias. Let $E^{j}$ be the expectation conditional on history $s^{j}$.

Proposition 1: Under a regime of futures markets, if preferences are: $(i)$ additively separable, then prices follow a martingale, that is, $P^{j}=E^{j}\left[P^{k}\right]$ for all $k>j$; (ii) homothetic, then with positive (negative) complementarity $U_{n z} \gtrless 0$, the futures price is a downward (upward) biased predictor of the later spot price $P^{j} \lessgtr E^{j}\left[P^{m}\right]$.

In the general theory of asset pricing, an asset's (excess) expected return rises with the covariance of its return with each investors' marginal utility of wealth. A "risk premium" is a reward that an asset must offer to compensate for the shortcoming of paying off more in states where wealth adds little to utility. In part (i) of Proposition 1, the covariance of the futures payoff with marginal utility is zero, because of certainty in the aggregate quantity of $N$. Writing the additively separable preferences as $U(n, z)=u(n)+v(z)$, then with common beliefs individuals trade to a Pareto optimal allocation in which each consumes a nonstochastic amount of $N .{ }^{16}$ It follows that the marginal utility of possessing one more unit of wealth at time $m$, which by a standard envelope condition is equal to the marginal utility of consuming one more unit of $N$, is constant across states.

In part (ii), the reason for downward bias when there is positive complementarity is easily seen when it is noted that, with homothetic preferences, the consumptions of $N$ are nonstochastic. ${ }^{17}$ Therefore the marginal utility of wealth is highest

\footnotetext{
${ }^{15}$ Unlike options pricing models, here there are no redundant securities. With more than two possible information outcomes at each event, more securities would be required to complete the market. This would introduce portfolio considerations which will not be our focus here.

${ }^{16}$ Proof: For any given allocation, replace each individual's consumption of $N$ with its expected value. This is feasible, and by additive separability of preferences, the concavity of $u(n)$, and Jensen's inequality, the new allocation yields a higher level of expected utility.

${ }^{17}$ Under homotheticity, the ratio of $N$ to $Z$ consumption in each state is the same for all individuals, and so is in proportion to the social totals; with constant aggregate supply of $N$, this implies that each individual's consumption of $N$ is nonstochastic.
} 
when consumption of $Z$ is high, which occurs when the spot price is low. So the futures contract pays off the least (in units of $N$ ) when marginal utility is high; this adverse risk characteristic leads to a positive premium for holding the futures contract, i.e., a downward bias. ${ }^{18}$

For the remainder of the paper, we assume additively separable preferences, so that part (i) of Proposition 1, which predicts martingale pricing, is the relevant case. Unbiasedness is not a general prediction about risk premia; it arises from three stylized features of the current model: separability, effectively complete markets, and nonrandom endowment of the numeraire. ${ }^{19}$ The martingale case will be useful for two reasons. First, it provides a clear counterexample to the proposition in partial equilibrium models that with risk-averse individuals, the futures price bias is upward or downward according to the sign of producer hedging. Second, it will serve as a baseline from which to highlight the effect of transaction costs on the premium examined in Section 3.

The counterexample shows that martingale pricing is consistent with either long or short hedging. In particular, Section 2.2 shows that, consistent with partial equilibrium models, here hedging by producers tends to be long or short according to the elasticity of demand. This will illustrate how the attempt of hedgers to transfer risk to risk-averse speculators need not produce any bias in the futures price.

\subsection{Optimal Hedging}

The basic intuition is captured by the case of a typical producer in a market with a single conclusive information arrival. Suppose that there are two types of agents, a representative producer/consumer, whose output of $Z$ is positively proportional to the aggregate output of $Z$, and a pure consumer, whose output of $Z$ is identically zero for all states. If spot demand for $Z$ is unitary elastic, then price and output move in inverse proportion, ${ }^{20}$ so if the grower does not trade, the numeraire value of his endowment is equal in the two states. Similarly, the value of a pure consumer's endowments is the same across states; if utility as a function of wealth were state independent, there would be no risk to transfer, and we would expect a zero hedge. ${ }^{21}$

\footnotetext{
${ }^{18}$ Homotheticity in part (ii) of Proposition 1 rules out wealth-induced differences in preferences, to ensure that higher aggregate output of $Z$ leads to higher (lower) marginal utility of $N$. A stronger version of part (ii) states that the futures price is a downward (upward) biased predictor of all later futures prices, not just the final spot price; this requires the additional assumption of a good-bad information structure, as defined in Section 3.

${ }^{19}$ Similar martingale results with nonrandom quantity of the numeraire were provided by $\mathrm{J}$. Hirshleifer (1977) in a two-state model, and Richard and Sundaresan (1981) in a continuous time setting. Salant (1976) stressed the sensitivity of this result to the assumption of additive separability.

${ }^{20}$ Throughout the paper, we refer to general equilibrium demand elasticity, that is, the percentage rate of change in gross demand for $Z$ as its spot price varies in response to shifts in the $Z$ endowment.

${ }^{21}$ Of course, here marginal utility is a function not only of wealth, but also of the random spot price. However, because marginal utilities of endowed wealth are affected by price in a similar way across states for both groups, futures positions with unitary elastic demand will still be null.
} 
With inelastic demand, a typical grower finds that the value of his $Z$ endowment is higher in the low output state, labelled $b$, than the high output state $a$, because low output $\bar{z}_{b}$ is more than offset by a disproportionately high spot price. So he is motivated to offer futures on sufficiently favorable terms to induce consumers to bear part of his (predominantly price) risk. The sale of a $1: 1$ bundle of claims to $Z$ in either state reduces the value of the grower's $Z$ holdings more in state $b$ than in state $a$, whereas the numeraire payment he receives is of the same value in either state. So selling futures short raises state- $a$ wealth and reduces state- $b$ wealth, which stabilizes the grower's endowed wealth gamble. With elastic demand, revenue is instead higher in state $b$, so the grower is motivated to go long in futures.

To formalize this argument with many trading rounds, we will assume the property of revenue ordering.

DEFINITION: Revenue ordering is said to obtain if at each information event $\theta^{j}$, the expected spot price $E^{j}\left[P^{m}\right]$ rises when the expected expenditure on $Z, E^{j}\left[P^{m} z^{m}\right]$ rises (falls) for inelastic (elastic) demand.

Proposition 2: Under the assumptions of representative producers and consumers, revenue ordering, and additively separable preferences, producers take long/short futures positions and consumers take short/long positions in all trading rounds if demand is elastic/inelastic.

Although one would normally expect revenue ordering to obtain, it could conceivably fail because of the nonlinear relationship between spot price, output, and sales revenue. As shown in Appendix 2, a specific case in which revenue ordering obtains is the additive logarithmic (LOG) family of utility functions

$$
U(n, z)=\alpha \log (n)+\log (z-\beta),
$$

where $\alpha$ and $\beta$ are constants, $\alpha>0$. Both elastic and inelastic spot demand for $Z$ is possible under LOG preferences, depending on the sign of $\beta$. Alternatively, revenue ordering will obtain under the assumption of a good-bad information structure as defined in Section 3.

The inelastic demand case of Proposition 2 is similar to Keynes' and Hicks' scenario, in that futures sales by producers to outsiders are a means of transferring price risks. However, since prices follow a martingale, there is no "normal backwardation" in the futures price. With elastic demand, contrary to normal backwardation theory, growers will hedge themselves by buying corn futures from consumers.

The direction of hedging in Proposition 2 matches the predictions of partial equilibrium models of producer hedging. And yet Proposition 1 showed that the prediction for bias of partial equilibrium analysis fails. In the example, futures price bias is unrelated to either demand elasticity or to the direction of aggregate hedging. Complementarity of preferences does not resolve the disagreement. As Part 2 of Proposition 1 showed, positive complementarity promotes downward 
bias regardless of elasticity of demand, while hedging will still tend to be long or short according to demand elasticity.

This demonstrates a significant inconsistency between the general versus partial equilibrium approaches. The full resolution of this dissonant chord will be deferred until the discussion of bias in Section 3 below. There we will see how setup costs of trading can reinstate the bias/hedging/elasticity relation. To identify more clearly the source of the discrepancy, recall that when demand is inelastic, producers desire to hedge short. The partial equilibrium argument is that outsiders require a downward bias to compensate for the risk of their long futures position; similarly, an upward bias results from elastic demand. This neglects the state-dependence in the indirect utility of wealth function of the traders.

Suppose, instead that besides trading corn futures, outsiders also eat corn. Then the marginal utility of ( $N$-denominated) wealth function depends not only on the trader's wealth, but on the price of corn. Traders optimally arrange their consumptions of $N$ to be level across states. Even though their wealth is not equated across states, they trade to where their marginal utility of wealth $\left(=u^{\prime}(n)\right)$ is. Therefore they are not on the margin willing to pay a premium for a security to shift contingent wealths across states.

A deeper understanding in terms of hedging pressure is provided by considering the consumption levels consumers would achieve if they were able to trade only in the final spot market, not in the prior futures markets. Consumers begin with a nonstochastic endowment of $N$, so without futures trading, their wealths are independent of state. Since the final spot price at which they can purchase $Z$ is random, they do bear consumption risk. With inelastic demand, a consumer spends more on corn when the price is high than when it is low, so a high price reduces his consumption of $N$. This implies high marginal utility of the numeraire. Thus, a long position is a good hedge for a consumer, because the futures contract pays off more when his marginal utility of wealth is higher. Similarly, with elastic demand short positions are good hedges for consumers.

It follows that consumers and producers are mutually hedging by taking the opposite sides of the futures transaction. Unlike the pure speculators of partial equilibrium models, consumers are not reluctant acceptors of futures positions. The hedging pressure of producers is met by a comparable hedging pressure of consumers. With additive preferences, these hedging incentives happen to offset precisely, so that neither group pays a premium.

\section{THE MODEL WITH POSITIVE TRANSACTION COSTS}

Because people diversify their consumption across commodities, but specialize in production, there are many more consumers than producers in any commodity market. When demand is inelastic, as is typical for agricultural commodities, and with costless trading, growers are predicted here to sell futures to consumers. The disproportion in numbers of the two groups implies that in the equilibrium of Section 2 the long futures position of a typical consumer is small compared with the short position of a typical producer. 
Few consumers actually trade futures, in contrast with the predictions of Section 2, as well as those of conventional models of asset pricing. Evidently, some fixed costs limit the participation of outsiders who do not have a stake in production. ${ }^{22} \mathrm{~A}$ fixed setup cost drives consumers, who would be small traders, rather than growers differentially from the futures market. This does not mean we apply the original model as if consumers did not exist, for though the actors are late, they arrive in time for the last scene, the spot market. The missing demand in the prior-to-final trading rounds biases the futures market price as compared to the model with costless exchange (as is formalized below).

The constriction of consumer demand for futures contracts (in the inelastic case) or supply of futures (elastic case) introduces downward and upward biases respectively in the futures price as a predictor of the spot price. Instead of a martingale, the benchmark case, there is systematic backwardation or contango according to demand elasticity. The larger the trading costs, the more consumers will be frozen out of the prior rounds, and so the larger the bias. For the inelastic case, this is reminiscent of Hicks' (1939) view that there is a congenital weakness on the demand side in futures markets, leading to "normal backwardation."

With many information arrivals and a fixed cost that is incurred before each futures trade, the number of futures participants after the first round of trading depends on the content of the initial information message, and so is itself a stochastic variable. We simplify here by assuming that there is only a one-shot setup cost $t$ (in numeraire units). An individual incurs a deadweight cost $t$ only at his first trade, so that he may trade at any later round without additional cost. (The one-shot assumption is reasonable if the cost of participation consists mainly of learning how to trade in futures, understanding the basic supply/demand characteristics of the market, or of searching for a good broker.)

The proposition that follows assumes that consumers rather than producers are driven by the fixed cost from the futures market. When there are many consumers relative to producers, the positions of consumers under zero transaction costs will be very small compared to producers. A sufficiently small transaction cost will therefore deter only consumers. ${ }^{23}$

Two technical assumptions are needed. First is that the spot price for $Z, P^{m}$ is a decreasing function of aggregate output. This could conceivably fail if there were a peculiar pattern of wealth effects. (Such a possibility could be ruled out by the stronger assumption of preferences which lead to aggregation, such as the LOG family or homothetic preferences.) The second assumption is that the arrival of information is unambiguously good or bad news, in the following sense.

\footnotetext{
${ }^{22}$ More generally, there are scale economies in trading on the individual level. Declining unit costs of trading are reflected in minimum contract sizes, brokerage commissions (to the extent that these are higher for smaller trades), and most importantly, the time and cognitive costs of learning to trade intelligently. Of course, costs may be reduced to some extent by trading through financial intermediaries (futures mutual funds). The fixed cost then would be the minimal cost per customer of transacting with the intermediary.

${ }^{23}$ For a larger setup cost, some producers may be driven from the futures market as well. But so long as a disproportionate number of demanders versus suppliers of futures are excluded, the tendency toward bias will remain.
} 
DEFINITION: A good-bad information structure is one in which $j=1, \ldots, m$, the distribution of aggregate output of $Z$ conditioned on history $s^{j-1}$ and event $a^{j}$ first order stochastically dominates the distribution given $b^{j}$.

Proposition 3: Under the assumptions of a good-bad information structure, a fixed setup cost of participation in the futures market, and that the spot price declines with aggregate output, if demand is inelastic/elastic, the futures price is a downward/upward biased predictor of the futures price at any later time, and of the later spot price.

The intuition for this result is easy to see in the case of a single information event (which automatically has a good-bad information structure). Consider inelastic demand. Producers hedge short, but since transaction costs deter some of their trading partners, they are not as short as they would be if trading were costless. So their wealth is higher in the high price state and lower in the low price state in comparison with a costless trading regime.

This means that the marginal utility of wealth, instead of being equated across states, is low when the futures payoff is high, ${ }^{24}$ leading to a positive risk premium. Thus the partial equilibrium result which failed in general equilibrium without transaction costs - to wit, that inelastic demand leads to downward bias and elastic demand to upward bias-is reinstated in a general equilibrium with transaction costs. ${ }^{25}$

This is despite the fact that qualitatively, the conclusions about hedging drawn in Section 2 are not greatly affected by the addition of transactions costs. Identical producers will still hedge long or short according to demand elasticity, although the amount by which they do so is reduced by an adverse risk premium effect. Consumers, of course, are affected since some will refrain from trading instead of taking small positions on the futures market.

A subtlety brought out by the model about multiple information arrivals is that if the information structure is ambiguous, the price bias might fail to correspond in the expected way with the direction of hedging. Instead of assuming good-bad stochastic dominance, suppose only that the expected output were higher in $a^{j}$ than $b^{j}$. Then even though the spot price decreases across final states with aggregate $Z$, it is possible for the expected spot price (and also, it turns out, the time $j$ futures price) to be higher in $a^{j}$ than in $b^{j}$. While atypical, this type of case may occur if the event is relatively uninformative about the level of $Z$, but materially affects variance or higher order moments.

\footnotetext{
${ }^{24}$ The trading cost makes the market bindingly incomplete, so that the efficient outcome of nonrandom consumption of $N$ is not achieved.

${ }^{25}$ The more general theme suggested here, that nonparticipation by consumers causes the direction of bias to be related to the hedging positions of producers, could lead to different predictions in other settings. For example, the inclusion of a second production stage would introduce another set of hedgers, processors of the commodity. Under inelastic demand, processors' positions would be complementary with those of growers (see D. Hirshleifer (1988b)). With limited participation by growers as well as consumers, this could lead to an upward rather than downward bias.
} 


\section{CONCLUSION}

Examining futures pricing in a multigood setting reveals some effects that are not present in partial equilibrium models. Proposition 1 showed that positive complementarity in preferences between consumption goods promotes downward futures price bias, and negative complementarity promotes upward bias. More importantly, contrary to the prediction of single-good partial-equilibrium theory, hedging pressure does not cause futures price bias in a model with costless trading. The paper has provided an example where the optimal futures hedging positions of identical growers are determined by demand price elasticity (Proposition 2). With additively separable preferences, futures prices are unbiased predictors of later spot prices regardless of demand elasticity (Proposition 1), even though hedging is long or short for elastic and inelastic demand respectively. With nonadditive preferences as well, there is no tendency for the bias to match the direction of producer hedging.

The divergence of these results from those of standard hedging pressure theory is due to allowing for hedging incentives of consumers, which are opposite to the hedging incentives of producers. However, the standard partial-equilibrium models are certainly realistic in (implicitly) assuming nonparticipation by consumers. This feature can be incorporated in a general equilibrium framework by adding a fixed setup cost of trading. Fixed costs of trading futures differentially drive the smaller traders (consumers) rather than the larger traders (producers) from the futures market. Allowing for trading costs reinstates the prediction of downward bias (backwardation) under inelastic demand, when producers hedge short; correspondingly, the model predicts upward bias (contango) for elastic demand, when producer hedging is long (Proposition 3). This effect, being systematic, is in contrast with the implications of imperfect-arbitrage models in which trading costs merely add a band of inaccuracy around the perfect markets baseline prediction.

This effect also contrasts with pricing relations derived from models with costless trading, which frequently can be obtained by assuming identical individuals, so that securities are priced to deter trading. Here, the predictions for bias arise from differential exclusion of some potential traders from the futures market, nonparticipation being a function of the endowments of the trader. The model therefore reflects in an essential way a feature of commodity futures markets which traditional theorists have considered important for pricing and the success of contracts: that the market brings about an interaction between distinct classes of traders, producers ("hedgers") and outsiders ("speculators").

In other contexts also, risks that are concentrated among a few traders should be more influential for pricing than dispersed risks. We would expect, for example, that the pricing of bonds and interest rate futures contracts would reflect more the hedging incentives of owners or managers of financial institutions than those of small homeowners.

The central theme of this paper may be summarized as follows. Partial-equilibrium models of commodity futures pricing are logically incomplete, since they neglect the consumption choice amongst different goods whose prices vary. 
However, they are realistic in an important respect-implicitly allowing for transaction costs. To combine logical completeness with realism, predictions should be derived from general equilibrium models that explicitly include the costs that limit market participation. This will sometimes, though not necessarily always, justify the predictions of partial-equilibrium models.

\section{Anderson Graduate School of Management, University of California, Los Angeles, CA 90024, U.S.A.}

Manuscript received January, 1988; revision received August, 1989.

\section{APPENDIX 1: Futures Prices with Costless Trading}

Proof of LemMa 1: A backwards recursion method is used. Contingent wealth $W_{s}^{m}$ as defined by (1) may be viewed as a consumption good for which investors will have an induced (state-dependent) utility function $V\left(W^{m} ; P^{m}\right)$. To show that at any time a dynamic trading strategy can be used to span the states of nature, consider first a shift in trading strategy of $\Delta \xi^{m-1}$ at $m-1$. This increases wealth by $\Delta W_{s}^{m}=\Delta \xi^{m-1}\left(P^{m(a)}-P^{m-1}\right)$ or $\Delta \xi^{m-1}\left(P^{m(b)}-P^{m-1}\right)$ after outcomes $a^{m}$ and $b^{m}$ respectively. Hence

$$
0=\Delta W_{a}^{m}\left[P^{m(b)}-P^{m-1}\right]-\Delta W_{b}^{m}\left[P^{m(a)}-P^{m-1}\right],
$$

where $a$ and $b$ abbreviate the states that follow $a^{m}$ and $b^{m}$, so the market at date $m-1$ is effectively complete so long as $P^{m(b)}, P^{m(a)} \neq P^{m-1}$. If $P^{m(b)} \neq P^{m(a)}$, then the former condition must hold, since otherwise a riskless arbitrage opportunity would be available.

Next, as inductive hypothesis assume spanning at an arbitrary time $j$. Let $S^{J}$ refer to the set of states which remain possible outcomes subsequent to history $s^{j}$. Spanning implies that there exist implicit state prices for terminal wealth $P_{W_{s}}^{j(a)}$ and $P_{W_{s}}^{J(b)}$ after outcomes $a^{J}$ and $b^{J}$ respectively such that

$$
\sum_{s \in S^{\prime(a)}} P_{W_{1}^{\prime(a)}}^{\prime\left(W_{s}^{J(a)}\right.}=0, \quad \sum_{s \in S^{(b)}} P_{W_{s}^{(b)}}^{\left(b W_{s}^{J(b)}\right.}=0
$$

where $\Delta W_{s}^{J}$ is defined as the change in terminal state-s wealth selected at date $j$. Let $\Delta^{J(a)}$ and $\Delta^{j(b)}$ be the shifts in dynamic trading strategy that generate the wealth shifts $\Delta W_{s}^{(a)}, s \in S^{J(a)}$ and $\Delta W_{s}^{(b)}, s \in S^{(b)}$. At $j-1$, consider a shift in position of $\Delta \xi^{-1}$ at $j-1$, followed by an offsetting shift of opposite sign at $j$ to close this position, and in addition the shifts $\Delta^{J(a)}$ and $\Delta^{J(b)}$. Then in addition to producing $\Delta W_{s}^{(a)}$ and $\Delta W_{s}^{J^{(b)}}$ for the remaining possible states, $P^{J^{(a)}}-P^{J^{-1}} \xi^{j^{-1}}$ extra units of wealth are provided in all states subsequent to $a^{J}$, and $P^{J^{(b)}}-P^{J^{-1}} \xi^{J^{-1}}$ extra units of wealth in all states subsequent to $b^{J}$. Hence, the total wealth shift brought about in state $s$ is

$$
\Delta W_{s}^{\prime-1}=\Delta W_{\uparrow}^{J}+\left(P^{J}-P^{J^{-1}}\right) \Delta \xi^{J-1} .
$$

So solving (6) for $\Delta W_{1^{\prime}}^{(a)}$ and $\Delta W_{s}^{J^{(b)}}$ and substituting into (5) gives

$$
0=\sum_{s \in S^{\prime}} P_{W_{1}}^{\prime}\left[\Delta W_{s}^{\prime-1}-\left(P^{J}-P^{J^{-1}}\right) \Delta \xi^{J-1}\right]
$$

Solving for and then eliminating $\Delta \xi^{j-1}$ in (7) as applicable after $a^{j}$ and $b^{j}$, and defining $K_{a} \equiv \sum_{s \in S^{\prime(1)}} P_{W_{1}^{\prime(a)}}$ and $K_{b} \equiv \sum_{s \in S^{\prime(b)}} P_{W_{s}(b)}$, then so long as $P^{J} \neq P^{J^{-1}}$, we obtain

$$
0=-K_{h}\left(P^{\prime(h)}-P^{\prime-1}\right) \sum_{s \in S^{\prime(a)}} P_{W_{s}}^{J(a)} \Delta W_{s}^{J-1}+K_{a}\left(P^{J(a)}-P^{J-1}\right) \sum_{s \in S^{\prime(b)}} P_{W_{s}^{\prime(b)}}^{J W_{s}^{J-1}} .
$$

This is a linear budget constraint on wealth shifts chosen at $j-1$, so since $P^{J^{(a)}} \neq P^{J(b)}$, the states are spanned by dynamic trading strategies initiated at $j-1$. Therefore, by induction, the market is effectively complete at all dates. 


\section{Semi-Contingent Markets}

It is convenient for later proofs to introduce an artifical trading regime, semi-contingent markets $(S C M)$, to describe the equilibrium in the assumed $F M$ regime. The efficient allocation achieved under $F M$ could be characterized by examining the trading problem of a one-shot complete market for contingent claims on the two goods. However, with additive separability or with homotheticity, since endowments and consumption of $N$ are nonrandom, contingent trading in $N$ is a degree of freedom for which traders have no use. It is therefore convenient to price contingent claims to $Z$ in terms of uncontingent claims to numeraire $N$. In $S C M$, which is also effectively complete, there is a single round of trading, and contingent claims to $Z$ are tradable. However, when a trader buys or sells units of $N$, the same quantity must be delivered in each state of the world.

We consider the decision of a trader on a semi-contingent market opened by surprise immediately following event $\theta^{J}$, so let $\bar{n}^{\prime}$ and $\bar{z}_{s}^{J}$ refer to the trader's position in $N$ and $Z$ at time $j$. Let $n^{J}$ be the final level of consumption of $N$ selected, $z_{s}^{J}$ be consumption of $Z$ in state $s$, and let $\phi_{s}^{J}$ be the price of a claim to state-s $Z$.

The trader's problem under $S C M$ is then

$$
\begin{aligned}
& \max _{n^{\prime},\left\{z_{s}^{\prime}\right\}, s \in S^{\prime}} E\left[u\left(n^{\prime}, \tilde{z}^{J}\right)\right] \quad \text { subject to } \\
& \bar{n}^{\prime}+\sum_{s} \phi_{s}^{\prime} \bar{z}_{s}^{\prime}=n^{\prime}+\sum_{s} \phi_{s}^{J} z_{s}^{J},
\end{aligned}
$$

where $\tilde{z}^{J}$ takes on value $z_{s}^{J}$ in state $s$. This yields the optimality conditions

$$
\frac{U_{z}\left(n^{J}, z_{s}^{\prime}\right)}{E^{\prime}\left[U_{n}\left(n^{\prime}, \tilde{z}^{\prime}\right)\right]}=\frac{\phi_{s}^{J}}{\pi_{s}^{J}}, \quad s \in S^{J} .
$$

Proof of Proposition 1: Suppose that a $S C M$ were opened at time $j$, and consumption positions selected. Next, suppose that agents were given a new opportunity to trade on a spot market opened at the final date $m$. With either separable or homothetic preferences, each individual's consumption of $N$ is constant across states, so that the initial $S C M$ is effectively complete. Thus, no retrading in the new spot market would take place. Applying (10) at time $m$ and at time $j$, dividing, and noting that $\phi_{s}^{m(s)}=P^{m(s)}$ shows that the market will clear if no-one trades at time $m$ $\left(n^{m}=n^{J}, z_{s}^{J}=z_{s}^{m}\right)$, and if the spot price is

$$
P^{m(s)}=\left(\frac{E^{\prime}\left[U_{n}\left(n^{J}, \tilde{z}^{J}\right)\right]}{U_{n}\left(n^{\prime}, z_{s}^{J}\right)}\right) \frac{\phi_{s}^{j}}{\pi_{s}^{J}} \equiv \frac{\phi_{s}^{J}}{w_{s}^{J}}, \quad \sum_{s \in S^{\prime}} w_{s}^{J}=1 .
$$

Since both $F M$ and $S C M$ are effectively complete, the price in the $F M$ regime of a futures contract must be the sum of the prices of the elements of the state claim bundle it provides:

$$
P^{\prime}=\sum_{s \in S^{\prime}} \phi_{s}^{\prime} .
$$

(i) With additive separability, since $n^{J}$ is constant, $U_{n}$ is nonstochastic. Hence, substituting for $\phi_{s}^{J}$ in (12) from (11),

$$
P^{\prime}=\sum_{s \in S^{\prime}} \pi_{s}^{\prime} P^{m(s)}=E^{\jmath}\left[\tilde{P}^{m}\right] .
$$

It follows by the rule of iterated expectations that

$$
P^{\prime}=E^{\prime}\left[E^{k}\left[\tilde{P}^{m}\right]\right]=E^{\prime}\left[\tilde{P}^{k}\right], \quad k>j .
$$

(ii) Let a similar ordering between two variables $x$ and $y$ be denoted by $x \sim y$, i.e., as one goes up so does the other. With positive complementarity, we have the similar ordering across states $U_{n}\left(n^{\prime}, z_{s}^{\prime}\right) \sim z_{s}^{\prime} \sim-P^{m(s)}$. (To see that $z_{s}^{J} \sim-P^{m(s)}$, note that with homotheticity we can view the final consumption choice as being made by a representative individual endowed with the same $N$, but with more $Z$ in state $s^{\prime}$ than state $s$. If $P^{m}$ were unchanged, then he would consume more of both $N$ and $Z$ in state $s^{\prime}$, if $P^{m}$ were to rise, then the opportunity set for net purchase [sale] of $N$ would be strictly improved [worsened], so by revealed preference he would also purchase more $N$ in state $s^{\prime}$, 
inconsistent with market clearing.) Hence

$$
P^{\prime}=\sum_{s \in S^{\prime}} w_{s}^{\prime} P^{m(s)}<\sum_{s \in S^{\prime}} \pi_{s}^{J} P^{m(s)}=E^{J}\left[\tilde{P}^{m}\right],
$$

where the inequality follows because probability weight is shifted toward lower prices under the martingale measure $w_{s}^{J}$ compared with the true probabilities $\pi_{s}^{J}$ in the first order stochastic dominance sense. The argument with negative complementarity is similar.

Q.E.D.

\section{APPENDIX 2: Optimal Hedging and Log Preferences}

Definition: Let wealth at time $j, W^{J}$ be the numeraire value of the agent's position as taken after information event $\theta^{\prime^{-1}}$ evaluated in terms of the prices of contingent $Z$ which would obtain if an $S C M$ market for final consumption claims were opened at time $j$. So

$$
W^{\prime}=n^{\prime-1}=\sum_{s \in S^{\prime}} \phi_{s}^{J_{s}^{j-1}}
$$

LemMA 2: With additively separable preferences, in a FM regime contingent wealths follow a martingale.

Proof of Lemma 2: First, it may be noted that by (11) that SCM prices follow a martingale, because at any time $j$, letting $k=m$,

$$
\phi_{s}^{\prime}=\pi_{s}^{\prime} \phi_{s}^{m}=E^{\prime}\left[\tilde{\phi}^{m}\right],
$$

where $\tilde{\phi}^{m}$ takes on value $\phi_{1}^{m}$ in state $s$, and 0 otherwise. It follows that at any time $j$, expected wealth is

$$
\begin{aligned}
E^{\prime}\left[W^{\prime+1}\right] & =E^{\prime}\left[n^{\prime}\right]+\sum_{s \in S^{\prime}}\left(E^{\prime}\left[\tilde{\phi}_{s}^{j+1}\right]\right) z_{s}^{J} \\
& =n^{\prime}+\sum_{s \in S^{\prime}} \phi_{s}^{J} z_{s}^{J},
\end{aligned}
$$

where $\tilde{\phi}_{s}^{\prime+1}$ is a random variable taking on the value of the $S C M$ price for state-s $Z$ that applies at time $j+1$ when event $\theta^{\prime+1}$ occurs. But by the $F M$ trading constraints (1),

$$
\begin{aligned}
E^{\prime}\left[W^{\prime+1}\right] & =n^{J-1}-P^{\jmath} \xi^{J-1}+\sum_{s \in S^{\prime}} \phi_{s}^{J}\left(z_{s}^{J-1}+\xi^{J-1}\right) \\
& =W^{\prime}+\xi^{J-1}\left(-P^{\jmath}+\sum_{s \in S^{\prime}} \phi_{s}^{\prime}\right) .
\end{aligned}
$$

The last term is zero, by (12), so wealth follows a martingale.

Q.E.D.

Proof of Proposition 2: 1. Similar Ordering of Consumption Bundles: Consumptions of $N$ are identical across states. By effective completeness, consumption of $Z$ is the same as it would be in a $S C M$ regime. By the $S C M$ optimality condition (10), since $v^{\prime}\left(z_{s}\right)$ is a strictly monotonic function of $z_{s}$ and the right hand side is the same for all individuals, consumption of $Z$ is similarly ordered (as one goes up, so does the other).

2. Ordering of Contingent Wealths and Spot Prices over States: To achieve similar ordering of consumption in an $F M$ regime, contingent wealth in the final trading rounds must, for all individuals, be ordered similarly across states. If demand is inelastic/elastic, then a trader's expenditure on $Z, P^{m} z^{m}$ is similarly/inversely ordered with $P^{m}$. Recalling that by effective completeness consumption $n$ is constant across states, it follows that to pay for this the wealth for each trader must be similarly/inversely ordered with spot price as demand is inelastic/elastic.

3. Ordering of Wealths and Futures Prices: Let us now verify how time $j$ wealths are ordered with respect to the futures price. Suppose that for event $\theta^{J}$, that $W_{a}^{J}>W_{b}^{J}$. Then since consumption of $N$ 
is the same in all states, it follows by Lemma 2 that $E_{a}^{J}\left[P^{m} z^{m}\right]>E_{b}^{J}\left[P^{m} z^{m}\right]$. By revenue ordering expected revenue is higher/lower when expected price is higher for inelastic/elastic demand, so

$$
E_{a}^{\prime}\left[P^{m}\right] \gtrless E_{b}^{\prime}\left[P^{m}\right] \quad \text { as demand is inelastic/elastic. }
$$

Since the futures price at time $j$ is equal to the expected value of the spot price,

$$
P_{a}^{\prime} \gtrless P_{b}^{\prime}, \quad \text { as demand is inelastic/elastic. }{ }^{26}
$$

4. Long and Short Positions: At time $j$, consumers' wealths satisfy

$$
W^{\prime}=P^{\prime} H^{\prime-1}+n^{-1},
$$

where $H^{\prime-1} \equiv \sum_{h=0}^{h=1-1} \xi^{h}$ is the total futures position at time $j-1$. So by (18) to make wealth similarly/inversely ordered with the futures price when demand is inelastic/elastic, a long/short total futures position must be taken by consumers. By market clearing, it follows that short/long positions are taken by producers.

Q.E.D.

ReVenue Ordering and Elasticity Properties of LOG Utility: We first show that for an individual with $L O G$ preferences, expenditure on $Z$ in the spot market, $P^{m} z^{m}$ is linearly related across states to the spot price $P^{m}$. In the final trading round, suppressing $m$ superscripts, the budget constraint is

$$
W=P z+n .
$$

This gives the optimality condition

$$
\frac{U_{n}}{U_{z}}=\frac{1}{P}
$$

For $L O G$ preferences (3), by (20) and (21) and solving for expenditure on $Z$,

$$
P z=\frac{n}{\alpha}+\beta P,
$$

where $n$ is optimally independent of state. Revenue ordering follows immediately by taking the expected value of (22), since $n$ is nonstochastic. To demonstrate that demand is elastic/inelastic as $\beta$ is $</>0$, solve (22) for $z$ and differentiate with respect to price.

Q.E.D.

\section{APPENDIX 3: Transaction Costs and Risk Premia}

Proof of Proposition 3: We will prove that futures price $P^{J}$ is a downward/upward biased predictor of $P^{j+1}, j=0, \ldots, m-1$, from which the proposition immediately follows.

1. Similar Ordering of Futures Traders' Marginal Utilities: The opportunity to trade futures in the rounds preceding the final spot market may be viewed as being equivalent to opening a complete market at time 0 in terminal wealths $W^{m}$. Traders have an indirect utility function $V\left(W^{m} ; P^{m}\right)$ for terminal wealth which is state dependent through $P^{m}$. So the effective completeness of the $F M$ regime implies a Pareto Optimal allocation of contingent wealths among those trading futures. (This is only efficient relative to the constraint that wealths cannot be shifted between futures traders and nontraders.) In such a constrained Pareto optimal allocation, all traders select similarly ordered marginal utilities of wealth across states, i.e., for all traders $i$ and $k, V_{W}^{t} \sim V_{W}^{k}$. For if marginal utilities crossed, i.e., $V_{W}\left(W_{l}^{m(s)} ; P^{m(s)}\right)<V_{W}\left(W_{l}^{m\left(s^{\prime}\right)} ; P^{m\left(s^{\prime}\right)}\right)$ for trader $i$, yet $V_{W}\left(W_{k}^{m(s)} ; P^{m(s)}\right)>$ $V_{W}\left(W_{k}^{m\left(s^{\prime}\right)} ; P^{m\left(s^{\prime}\right)}\right)$ for trader $k$, then they could jointly raise their expected utilities by agreeing that $i$ gives $\varepsilon$ units of state-s wealth to $k$ in return for $\varepsilon\left(\pi^{s} / \pi^{s^{\prime}}\right)$, of state-s' wealth, $\varepsilon$ small.

2. Ordering of Marginal Utilities with the Spot Price: Consider now the final spot market after $\theta^{m}$ arrives. By a standard envelope condition for a single-round consumption decision, $\partial V(W ; P) / \partial W=$ $u^{\prime}(n)$ ( $m$ superscripts suppressed). So traders' marginal utilities are inversely ordered across states

${ }^{26}$ So long as demand elasticity is not unitary, then since by assumption prices differ, $P_{a}^{\prime} \neq P_{b}^{\prime}$, wealths must be unequal. 
with final consumption of $N$. Since $V_{W}(W ; P)$ is similarly ordered for all traders across states, traders order similarly their consumptions of $N$ as well, $n^{t} \sim n^{k}$.

By the definition of spot demand elasticity, for given wealth the expenditure on $Z$ increases (decreases) with the spot price of $Z$ if demand is inelastic (elastic). The wealth of a consumer who does not trade futures equals his endowed quantity of $N$, which is the same across states. Let an $r$ superscript indicate a consumer who refrains from trading. Since his expenditure on $Z$ increases (decreases) with the spot price for inelastic (elastic) demand, $P z^{r} \sim P(-P)$, his consumption of $N, W-P^{r} z^{r}$, decreases (increases) with $P$, so $-n^{r}\left(n^{r}\right) \sim P$.

Since traders similarly order their consumptions of $N$, which in the aggregate (net of costs $t$ ) is nonrandom, by adding up of social totals the consumption of $N$ by traders increases (decreases) with $P$, i.e., $n^{t}\left(-n^{t}\right) \sim P$. It follows by the envelope condition that for inelastic/elastic demand, marginal utility of traders $-V_{W}^{t}(W ; P)\left(V_{W}^{t}(W ; P)\right) \sim P$.

3. Bias: We will now show that the futures price must be biased appropriately, since no change in an optimal trading strategy can increase expected utility. Starting after event $\theta^{\prime}$, let the possible prices at time $j+1$ be $P^{(j+1) a}$ and $P^{(j+1) b}$. Consider an increase in the futures position $\xi^{j}$ by $\varepsilon$, which is closed at $j+1$ by a sale of $\varepsilon$ units of futures. Any profits or losses from this perturbation in the trading strategy shows up as a (negative) increase in wealth $W^{m}$ of $\left(P^{(\jmath+1) a}-P^{J}\right) \varepsilon$ in each state which can arise subsequent to $a^{j+1}$, and an increase of $\left(P^{(J+1) b}-P^{J}\right) \varepsilon$ in each state arising subsequent to $b^{\prime+1}$.

The impact of the trading perturbation on expected utility is

$$
\begin{aligned}
\frac{d E^{\prime}\left[V\left(W^{m} ; P^{m}\right)\right]}{d \xi^{\prime}}= & \operatorname{Pr}\left(a^{\jmath+1} \mid s^{\jmath}\right) E^{(\jmath+1) a}\left[\frac{d W^{m}}{d \xi^{\jmath}} V_{W}\right] \\
& +\operatorname{Pr}\left(b^{\jmath+1} \mid s^{\jmath}\right) E^{(\jmath+1) b}\left[\frac{d W^{m}}{d \xi^{\jmath}} V_{W}\right]
\end{aligned}
$$

where

$$
\frac{d W^{m}}{d \xi^{j}}= \begin{cases}P^{(1+1) a}-P^{J}<0 & \text { if } a^{j+1} \text { occurs, } \\ P^{(1+1) b}-P^{J}>0 & \text { if } b^{j+1} \text { occurs. }\end{cases}
$$

The inequalities above must hold, because labeling $a^{\jmath+1}$ so that $P^{(\jmath+1) a}<P^{(\jmath+1) b}$, if either failed it would be possible through either a long or short perturbation to increase wealth in all states subsequent to both outcome $a^{\prime+1}$ or $b^{j+1}$. With a good-bad information structure, the distribution of $Z$ given $a^{\prime+1}$ first order dominates the distribution given $b^{j+1}$. The spot price is decreasing with aggregate $Z$, and is monotonic across states with the marginal utilities of traders. It follows that the distribution of traders' marginal utilities given event $a^{j+1}$ is greater (lower) than that given event $b^{j+1}$ for inelastic (elastic) demand, so $E^{(j+1) a}\left[V_{W}\right] \gtrless E^{(j+1) b}\left[V_{W}\right]$ for inelastic (elastic) demand.

Consider the case of inelastic demand. By (23), setting to zero the gain from perturbing the optimal trade,

$$
\begin{aligned}
0= & \left(E^{(\jmath+1) a}\left[V_{W}\right]\right)\left[\operatorname{Pr}\left(a^{\jmath+1} \mid s^{\jmath}\right) P^{(\jmath+1) a}+\operatorname{Pr}\left(b^{\jmath+1} \mid s^{\jmath}\right) P^{(\jmath+1) b}-P^{\jmath}\right] \\
& -\left(E^{(\jmath+1) a}\left[V_{W}\right]-E^{(\jmath+1) b}\left[V_{W}\right]\right) \operatorname{Pr}\left(b^{\jmath+1} \mid s^{\jmath}\right)\left[P^{(\jmath+1) b}-P^{\jmath}\right] .
\end{aligned}
$$

Since the subtracted term is positive, the first term is also positive, so $P^{J}<E^{\jmath}\left[P^{J+1}\right]$. The argument for elastic demand is similar.

Q.E.D.

\section{REFERENCES}

Anderson, Ronald W., and Jean-Pierre Danthine (1983): “Hedger Diversity in Futures Markets," Economic Journal, 93, 370-389.

Breeden, Douglas (1980): “Consumption Risk in Futures Markets," Journal of Finance, 35, $503-520$.

(1984): "Futures Markets and Commodity Options: Hedging and Optimality in Incomplete Markets," Journal of Economic Theory, 32, 275-300.

BritTo, R. (1984): “The Simultaneous Determination of Spot and Futures Prices in a Simple Model with Production Risk," Quarterly Journal of Economics, 99, 351-365.

ChANG, ERIC (1985): "Returns to Speculators and the Theory of Normal Backwardation," Journal of Finance, 40, 193-208. 
Cox, John, Stephen Ross, and Mark Rubinstein (1979): “Options Pricing: A Simplified Approach," Journal of Financial Economics, 7, 229-263.

Duffie, DarRell, AND ChI-Fu HuAng (1985): “Implementing Arrow-Debreu Equilibria by Continuous Trading of Few Long-Lived Securities," Econometrica, 54, 1161-1184.

Grauer, Frederick L. A., AND Robert H. Litzenberger (1979): "The Pricing of Commodity Futures Contracts Nominal Bond and Other Risky Assets under Commodity Price Uncertainty," Journal of Finance, 34, 69-83.

GRAy, ROBERT W. (1960): "The Characteristic Bias in Some Thin Futures Markets," Food Research Institute Studies, 2, 296-312.

Hicks, JoHN R. (1939): Value and Capital. Cambridge: Oxford University Press, pp. 135-140.

HiRShleIfER, David (1988a): “Residual Risk, Trading Costs, and Commodity Futures Risk Premia," Review of Financial Studies, 1, 173-193.

(1988b): "Risk, Futures Pricing, and the Organization of Production in Commodity Markets," Journal of Political Economy, 96, 1206-1220.

HiRSHLEIFER, JACK (1977): "The Theory of Speculation Under Alternative Regimes of Markets," Journal of Finance, 32, 975-999.

KeYNeS, JOHN MAYNARD (1923): "Some Aspects of Commodity Markets," Manchester Guardian Commercial, European Reconstruction Series, Section 13, 784-786.

KrePS, David (1982): "Multiperiod Securities and the Efficient Allocation of Risk: A Comment on the Black-Scholes Option Pricing Model," in The Economics of Information and Uncertainty, ed. by J. J. McCall. Chicago: University of Chicago Press.

MAYERS, DAvid (1972): “Non-Marketable Assets and Capital Market Equilibrium under Uncertainty," in Studies in the Theory of Capital Markets, ed. by M. Jensen. New York: Praeger.

Newbery, David M. G. (1983): "Futures Trading, Risk Reduction and Price Stabilization," Ch. 9 in Futures Markets, ed. by M. Streit. London: Basil Blackwell.

Newbery, David M. G., AND Joseph E. Stiglitz (1981): The Theory of Commodity Price Stabilization: A Study in the Economics of Risk. Oxford: Clarendon Press.

Richard, SCOTT, AND SURESh SUNDARESAN (1981): "A Continuous Time Equilibrium Model of Forward Prices and Futures Prices in a Multigood Economy," Journal of Financial Economics, 9, 347-371.

Rolfo, JACQUes (1980): “Optimal Hedging Under Price and Quantity Uncertainty: The Case of a Cocoa Producer," Journal of Political Economy, 88, 100-116.

Salant, StePhen W. (1976): "Hirshleifer on Speculation," Quarterly Journal of Economics, 90, $667-676$

Stein, Jerome (1961): “The Simultaneous Determination of Spot and Futures Prices," American Economic Review, 51, 1012-1025.

Stiglitz, JOSEPH E. (1983): “Futures Markets and Risk: A General Equilibrium Approach,” in Futures Markets, ed. by M. Streit. London: Basil Blackwell.

Stoll, Hans (1979): "Commodity Futures and Spot Price Determination and Hedging in Capital Market Equilibrium," Journal of Financial and Quantitative Analysis, 14, 873-894. 